P0182

\title{
HAZARD DETECTION: TESTING THE CAVEATS OF PREVIOUS STUDIES
}

\author{
Steve Fotios et al.
}

DOI 10.25039/x46.2019.PO182

from

CIE x046:2019

\section{Proceedings}

of the

29th CIE SESSION

Washington D.C., USA, June 14 - 22, 2019

(DOI 10.25039/x46.2019)

The paper has been presented at the 29th CIE Session, Washington D.C., USA, June 14-22, 2019. It has not been peer-reviewed by CIE.

\section{(C) CIE 2019}

All rights reserved. Unless otherwise specified, no part of this publication may be reproduced or utilized in any form or by any means, electronic or mechanical, including photocopying and microfilm, without permission in writing from CIE Central Bureau at the address below. Any mention of organizations or products does not imply endorsement by the CIE.

This paper is made available open access for individual use. However, in all other cases all rights are reserved unless explicit permission is sought from and given by the CIE.

CIE Central Bureau

Babenbergerstrasse 9

A-1010 Vienna

Austria

Tel.: +43 17143187

e-mail: ciecb@cie.co.at

www.cie.co.at 


\title{
HAZARD DETECTION: TESTING THE CAVEATS OF PREVIOUS STUDIES
}

\author{
Fotios, S. ${ }^{1}$, Mao, Y. ${ }^{1}$, Yao, Q. ${ }^{2}$ \\ 1 University of Sheffield, Sheffield, UNITED KINGDOM \\ ${ }^{2}$ Shenzhen University, Shenzhen, CHINA \\ steve.fotios@sheffield.ac.uk
}

DOI 10.25039/x46.2019.PO182

\begin{abstract}
Detecting pavement irregularities that might lead to a fall if not seen in sufficient time is one of the critical visual tasks of pedestrians. Experiments have been conducted to determine how the detection of peripheral objects, at mesopic light levels, is affected by light level and spectrum, leading to proposals for new guidance. As with all experimental work, there are caveats to application of the findings in practice - limitations regarding the context in which the experiment was conducted. This paper presents three experiments carried out to explore those caveats.
\end{abstract}

Keywords: Obstacle detection, facial emotion recognition, glare.

\section{Background}

A critical visual task for pedestrians is the detection of pavement hazards likely to cause a trip or fall if not seen in sufficient time to make changes to gait (Caminada and van Bommel, 1984; Fotios et al., 2015). Pedestrian falls are a significant societal problem (Berntman, 2015; Bird, 2008; Frith and Thomas, 2010; Mindell et al., 2012).

After dark, one intended benefit of road lighting is that it enhances the probability of detecting pavement hazards. Recent experimental studies (Fotios and Cheal, 2009; 2013, Uttley et al., 2017) have examined how the detection of pavement hazards is affected by changes in the illuminance from road lighting. For a critical hazard the optimal illuminance is approximately 1.0 lux. Further increase in illuminance brings negligible improvement in detection performance. The critical hazard was defined as a $10 \mathrm{~mm}$ variation in vertical height, much smaller than the previously assumed $25 \mathrm{~mm}$ threshold, and this was determined using data regarding foot clearance and injuries (Fotios and Uttley, 2018). However, the experiments were conducted using simplified situations which raise questions of the extent to which the results can be safely generalised to wider situations. In particular, the hazards were always raised above ground level (i.e. they resembled kerbs, but not pot holes) and detection was not impaired by either disability from glare or performance of a parallel task. This paper describes further experimental work carried out to explore the significance to application of these three caveats.

\section{General method}

The detection of peripheral objects was examined in a scale model, a chamber approximately $1,2 \mathrm{~m}$ wide, 1,2 $\mathrm{m}$ deep, and 1,2 $\mathrm{m}$ high, with four obstacles at floor level (Figure 1). Test participants looked towards a small LCD screen on the rear wall of the apparatus at the same height as the participant's eye. In order to place the obstacle detection task in the peripheral visual field, a concurrent fixation task (number recognition) was displayed on a small LCD screen mounted in the centre of the back wall of the booth. Two random single digit numbers (1 to 9) were presented sequentially within the $500 \mathrm{~ms}$ duration of each trial (regular Arial font, $100 \mathrm{~mm}$ high, subtending $2,57^{\circ}$ at the participant's eye, white digits of luminance $0,25 \mathrm{~cd} \cdot \mathrm{m}^{-2}$ on a black background). This simple digit-recognition task was used to promote foveal viewing and measure (approximately, according to recognition accuracy) the degree to which foveal viewing was maintained.

The floor of the apparatus contained four cylinders, normally flush with the floor of the apparatus, but which could be raised or lowered by incremental amounts. The five simulated 
vertical sizes (height or depth) examined were $4 \mathrm{~mm}, 6 \mathrm{~mm}, 10 \mathrm{~mm}, 16 \mathrm{~mm}$ and $25 \mathrm{~mm}$ : the obstacle sizes presented in trials were scaled to subtend the same visual angle at the eye when observed in the test apparatus as if observed at ground level 3,4 m ahead.

The chamber was lit from overhead by LED light fittings. Test illuminances are as measured on the top surface of obstacle 1 when flush with the surrounding pavement. In all three experiments the overhead lighting was set to a spectrum providing an S/P ratio of 1,6 (CCT approximately $2600 \mathrm{~K}$ ).

In a trial, the scene was observed for $500 \mathrm{~ms}$ (as controlled by the occlusion glasses); one of the four obstacles were raised (or lowered) to one of the five heights and the participant reported which, if any, of the obstacles were raised. To assess false positive responding, null condition trials were included. Experiment sequences were randomised. Data were analysed using correct detection rate plotted against target height.
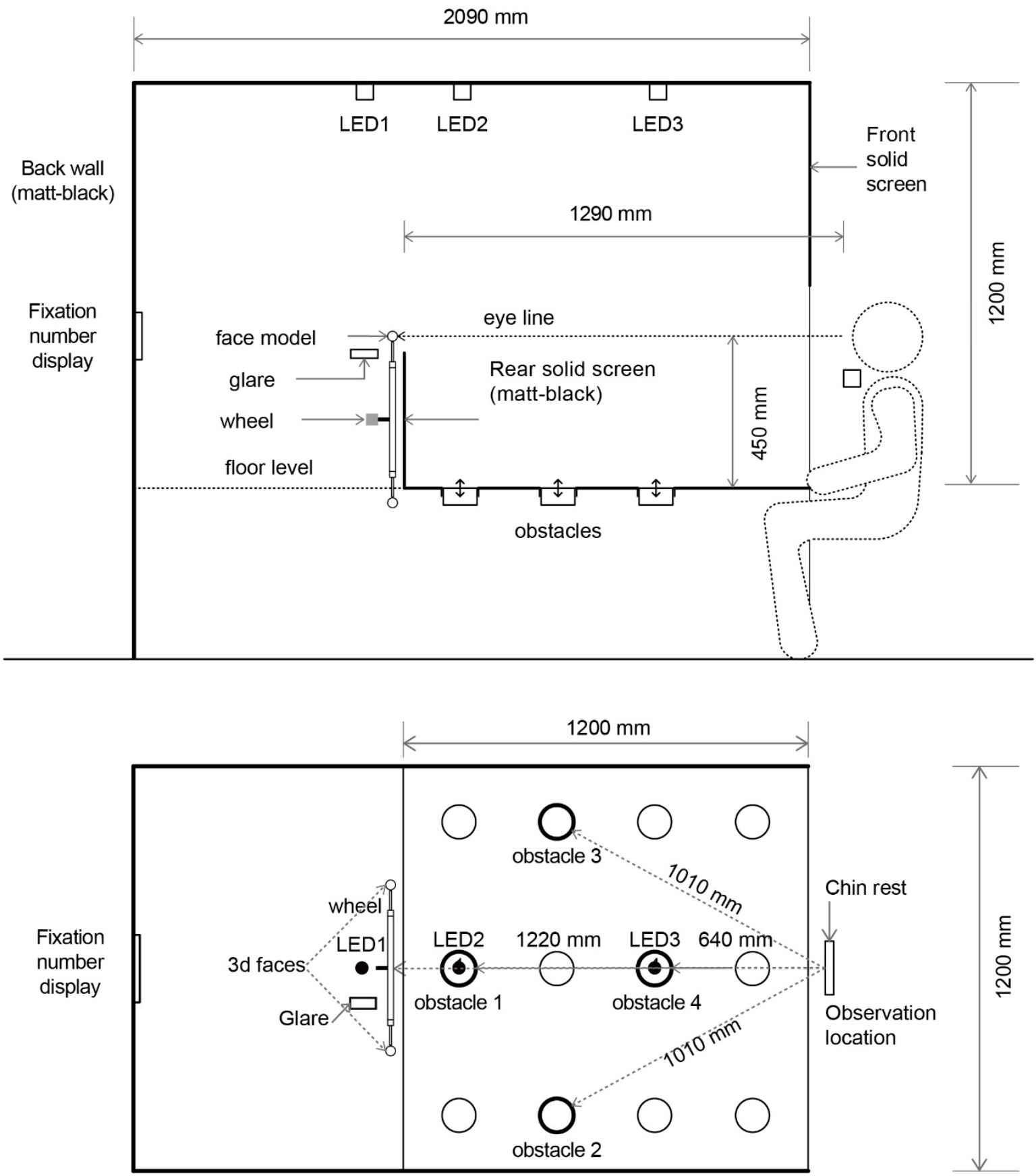

Figure 1 - Plan and section of the apparatus 
Each experiment was given approval through University of Sheffield ethical committee. Informed consent was gained from each test participant prior to trials.

\section{Experiment 1: Raised and lowered hazards}

Experiment 1 compared the detection of raised and lowered targets (Fotios et al., 2019). There were three lighting conditions, LED 1, 2 and 3 used in separate trials, with each providing the same illuminance $(1,0$ lux $)$ at the target location. Here we present the results as averaged across all three light source positions. Detection targets were raised and lowered cylinders. There were 20 participants (aged 19 to 35 years, $50 \%$ male) in a repeated measures design.

The fixation target was correctly identified in $97 \%$ of trials, which suggests a reasonable degree of foveal fixation. There were $238(24,6 \%)$ false alarms within the 960 null condition trials: $d^{\prime}=3,28$. The results (Figure 2) suggested a significant effect of obstacle height (or depth) with greater variation in height being detected with greater frequency $(p<0,001)$. However, the results did not suggest a significant difference in the detection of raised and lowered obstacles of the same variation in vertical height $(p=0,41)$.

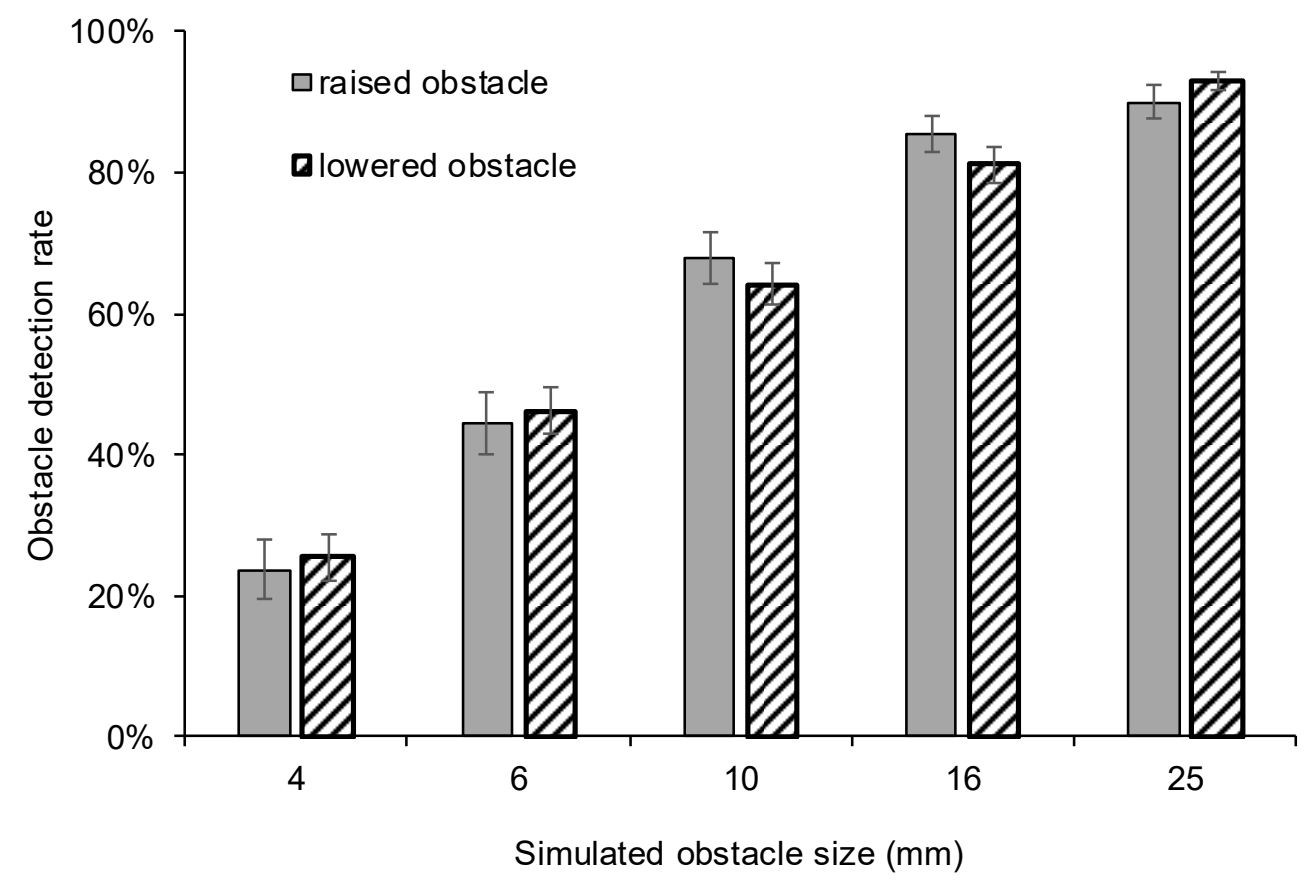

Figure 2 - Mean detection rate plotted against obstacle height for obstacles either raised or lowered relative to the surrounding surface. error bars show the standard error of the mean

\section{Experiment 2: Disability from glare}

Experiment 2 examined the influence of glare. There were four lighting conditions, target illuminances of $0,2 \mathrm{lux}, 0,6 \mathrm{lux}, 2,0 \mathrm{lux}$ and 6,3 lux, all with the same $\operatorname{SPD}(\mathrm{S} / \mathrm{P}$ ratio $=1,6$, CCT $=2800 \mathrm{~K}$ ), with only LED2 being used in this experiment. A glare source was positioned at the same vertical height as the fixation mark, $2,64^{\circ}$ to the left, and subtended a visual angle of $0,87^{\circ}$ at the observer's eyes. The glare source provided 0,55 lux as measured in the vertical plane at the observation position $(\mathrm{S} / \mathrm{P}$ ratio $=1,6)$. The glare source was intended to simulate the headlamps of an oncoming vehicle. The targets were all lowered cylinders. There were 20 participants (aged 19 to 33 years, $60 \%$ males).

The fixation target was correctly identified in $97 \%$ of trials, which suggests a reasonable degree of foveal fixation. There were $104(16,3 \%)$ false alarms within the 640 null condition trials: $d^{\prime}=1,53$. Figure 3 shows the detection rates plotted against horizontal illuminance. At the lower illuminance $(0,2 \mathrm{lux})$ the presence of glare resulted in a significant reduction in 
detection rate at four smaller heights (t-test, $p \leq 0,001$ ): at the three higher illuminances, the results did not suggest a significant effect of glare on hazard detection rate. This confirms that glare can affect detection rate, as expected, but should not be used to determine optimal conditions. This experiment used glare of only one illuminance, size and position: variations in these are likely to change the threshold at which glare leads to significant detriment in detection.

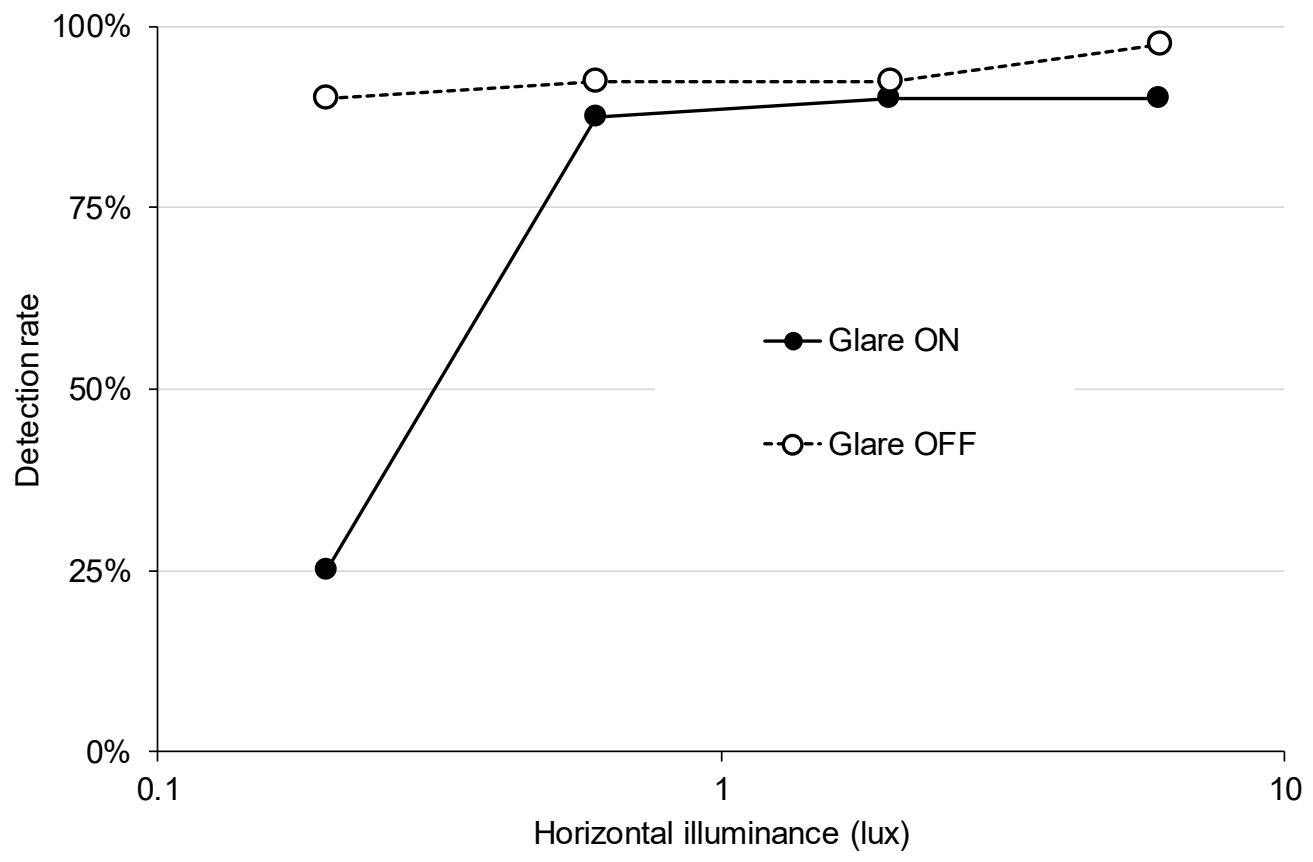

Figure 3 - Detection rate plotted against illuminance for trials with glare source switched on and off

\section{Experiment 3: Parallel tasks}

Experiment 3 tested obstacle detection performance in parallel with a facial emotion recognition (FER) task. FER is the evaluation of emotion as conveyed by facial expression and has been recommended as a suitable procedure for investigating lighting and interpersonal judgements (Fotios and Johansson, 2019). In this experiment, the fixation target was replaced by an aperture behind which could be revealed a 3D face model (Figure 4). There were 9 faces, of which three presented a happy expression, three a neutral expression, two an angry expression and one a sad expression. In a given $500 \mathrm{~ms}$ exposure to the scene, either a face alone, an obstacle alone, both together, or neither were represented. The faces were presented face-towards the observer. The faces were fitted to a vertical wheel, allowing rapid (and automatically controlled) variation of the face (if any) presented in a specific trial.

The experiment was conducted at two light levels, 1 lux and 10 lux, these giving luminances of $0,15 \mathrm{~cd} \cdot \mathrm{m}^{-2}$ and $1,5 \mathrm{~cd} \cdot \mathrm{m}^{-2}$ on the target face. In each trial, the test booth was lit from above by both LED2 and LED3 together. LED1 was not used. Detection targets were raised and lowered cylinders. The observer was required to orally report which expression was portrayed by the face, if shown, to press a response button if an obstacle was present, and to do nothing if there were no faces or hazards (null condition trials). There were 30 participants (aged 19 to 35 years, $50 \%$ males).

There were $468(15,6 \%)$ false alarms within the 3000 null condition trials: d' $=1,44$. (For the FER trials, the false alarm rate was only $0,003 \%$ ). Figure 5 shows detection rate plotted against obstacle size for the two light levels for trials with and without the parallel FER task. For the smallest obstacle size detection performance approaches chance level for all four conditions and increases for larger obstacle sizes. While Figure 5 suggests that detection rate 
at 10 lux was greater than at 1 lux this was not a significant effect (ANOVA, $p=0,26$ ). This is as expected from previous results. However, obstacle detection performance was reduced when conducted in parallel with the FER task $(p<0,001)$.

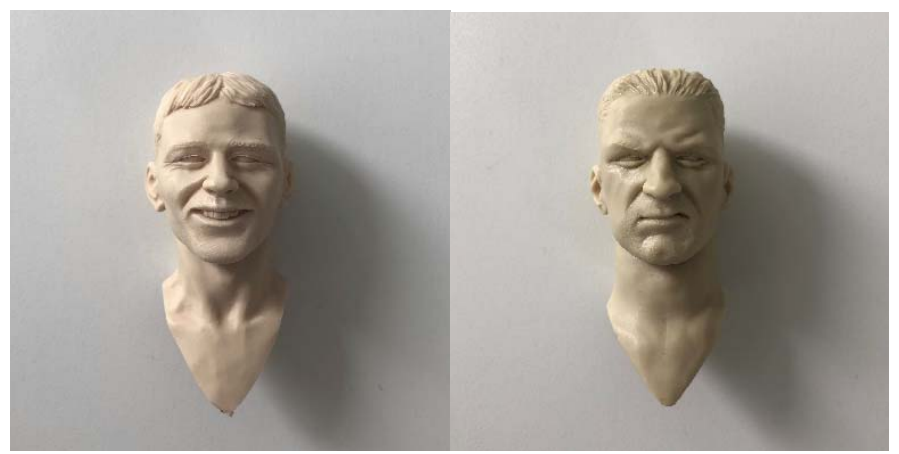

Figure 4 - Examples of the 3D face models, showing happy (left) and angry (right) expressions

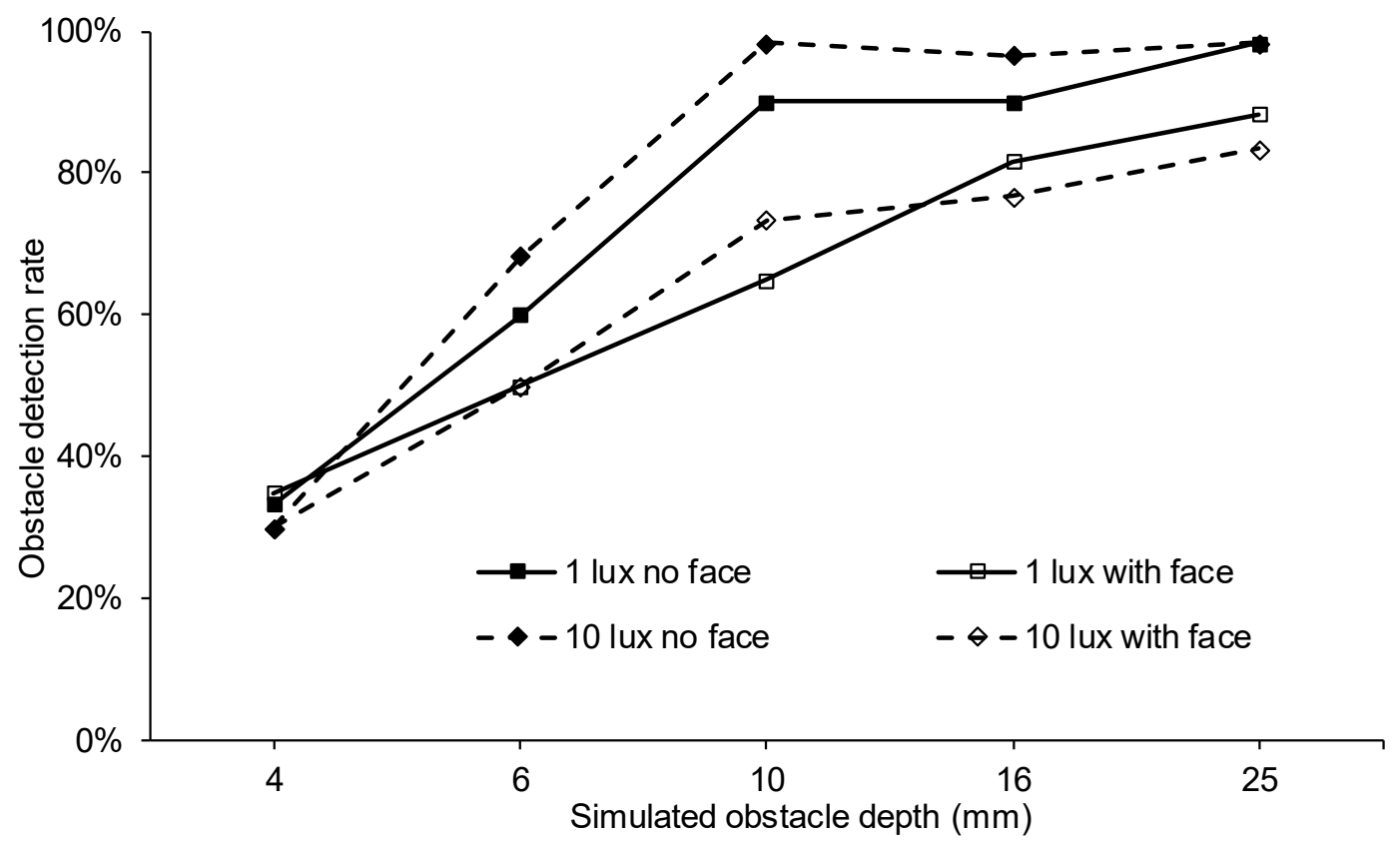

Figure 5 - Detection rate plotted against obstacle depth for two illuminances (1 lux and 10 lux as measured at the obstacle) for trials with and without a simultaneous FER target

\section{Conclusions}

The aim of this work was to test three of the caveats associated with previous work which has led to a proposed horizontal illuminance of 1,0 lux as being optimal for obstacle detection. These results suggest that detection is not affected by whether the trip hazard is raised or lowered relative to the pavement surface but is affected by disability due to glare and by performance of a parallel task.

The presence of glare reduced detection ability at the lowest of the four illuminances used in experiment 2. Only one glare source illuminance was used (chosen to represent a typical headlight), and if a higher illuminance were used that could lead to significant detection detriment at higher road lighting illuminances. One way to account for this would be to establish a representative set of glare sources and use disability glare models such as CIE146:2000 a model to establish the threshold adaptation illuminance at which the impairment due to glare transfers between the escarpment and plateau. Note that for the conditions of this experiment, disability glare did not have significant effect at the proposed design minimum of 1,0 lux. Detection performance was reduced when participants were also 
responding to the FER task. In those situations where pavement obstacles are likely (such as a cobbled street) then designers may consider increasing the horizontal illuminance.

There are further caveats to the generalisation of obstacle detection findings to application. These include light source, observer and hazard geometry: changes in these relative locations will affect the contrast and size of the obstacle and the shadow it casts. The effect of observer age has been examined in previous work (Fotios and Cheal, 2009, Uttley et al., 2017): only at low illuminances do older people have significantly worse detection performance than younger people, with the effect of age being non-significant at the proposed minimum of 1,0 lux.

\section{Funding}

This work was carried out with support from the Engineering and Physical Sciences Research Council (EPSRC) grant number EP/M02900X/1.

\section{References}

BERNTMAN, M. 2015. Fotgängares olyckor och skador i trafikmiljö med fokus på fallolyckor (in Swedish) Pedestrian accidents and injuries in traffic environment with focus on fall accidents. Bulletin 295. Department of Technology and Society, Traffic and Roads, Lund University, LTH.

BIRD, S. 2008. The risk of tripping accidents on public footways. P I Civil Eng-Munic., 161, $129-136$.

CAMINADA, J.F., VAN BOMMEL, W.J.M. 1984. New lighting criteria for residential areas. J Illum Eng Soc., 13, 350-358.

FOTIOS, SA., CHEAL, C. 2009. Obstacle detection: A pilot study investigating the effects of lamp type, illuminance and age. Lighting Res. Technol., 41, 321-342.

FOTIOS, S., CHEAL, C. 2013. Using obstacle detection to identify appropriate illuminances for lighting in residential roads. Lighting Res. Technol., 45, 362-376.

FOTIOS, S., JOHANSSON, M. 2019. Appraising the intention of other people: Ecological validity and procedures for investigating effects of lighting for pedestrians. Lighting Res. Technol., 51, 111-130.

FOTIOS, S., MAO, Y., UTTLEY, J., CHEAL, C. [Forthcoming]. Road lighting for pedestrians: Effects of luminaire position on the detection of raised and lowered trip hazards. Lighting Res. Technol., DOI: doi.org/10.1177/1477153519827067/

FOTIOS, S., UTTLEY, J. 2018. Illuminance required to detect a pavement obstacle of critical size. Lighting Res. Technol., 50, 390-404.

FOTIOS, S., UTTLEY, J., CHEAL, C. and HARA, N. 2015. Using eye-tracking to identify pedestrians' critical visual tasks. Part 1. Dual task approach. Lighting Res. Technol., 47, 133-148.

FRITH, W., THOMAS, J. 2010. The mechanisms and types of non-motor vehicle injuries to pedestrians in the transport system and indicated infrastructure implications. NZ Transport Agency research report 431. Wellington: NZ Transport Agency.

MINDELL, J.S., LESLIE, D., Wardlaw, M. 2012. Exposure-based, 'like-for-like' assessment of road safety by travel mode using routine health data. PLoS ONE 2012. 7.

UTTLEY, J., FOTIOS, S., CHEAL, C. 2017. Effect of illuminance and spectrum on peripheral obstacle detection by pedestrians. Lighting Res. Technol., 49, 211-227. 